\title{
A Spousal Joint Decision Making Exercise: Do Couples Perceive Differences In Influence Tactics Used In Decisions Involving Differing Product Categories And Levels Of Product Disagreement?
}

Cheryl B. Ward, (E-mail: cward@mtsu.edu), Middle Tennessee State University

\begin{abstract}
Past research has indicated that husbands and wives often employ influence tactics to attempt to sway their spouses toward making a final purchase decision (Kirchler 1993, 1995; Nelson 1988; Spiro 1983). This study explores whether those influence tactics differ based on whether couples face product choices in across or within product categories. Also of interest is whether the initial level of disagreement (high or low) experienced by the couple regarding the likelihood of product purchase impacts use of influence tactics in the final joint decision. Given the increased possibility of conflict between spouses when faced with purchase decisions involving different product categories, it is expected that couples will employ a greater level of influence tactics in an effort to persuade their partners in the decision making process and, at the same time, minimize the likelihood of open conflict. It is also thought that higher initial disagreement will be more likely to result in the use of influence tactics in the final joint product decision than lower levels of disagreement. This study found support for these predictions.
\end{abstract}

\section{INTRODUCTION}

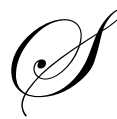

pousal decision behavior is key to understanding how families reach purchase decisions ( $\mathrm{Su}$, Fern, and Ye 2003, p. 277)." While researchers have long been interested in how families arrive at purchase decisions, it has not been until recently that researchers have attempted to relate their findings to marketing strategy. Recently, authors have suggested that marketers may use an improved understanding of family decision making tactics to guide personal selling activities (Aribarg, Arora, and Bodur 2002), to target communication messages (Arora and Allenby 1999), and to shape brand choice (Seetharaman, Ainslie, and Chintagunta 1999).

For example, Aribarg, Arora, and Bodur (2002) found that the effectiveness of salesperson strategies to encourage revision versus concession in a joint spousal purchase procedure is impacted by the couples' interaction and concession actions at the point of purchase. Given that repeat business and word-of-mouth communication is largely based on purchase satisfaction, the ability of the salesperson to successfully communicate objective information to facilitate positive joint spousal decisions may be tantamount to ensuring company longevity.

Arora and Allenby (1999) suggested that company's may more effectively spend their advertising dollars by targeting communication messages to group members who have a higher influence on the specific aspects of the decision. This suggestion acknowledges that husbands and wives, who may not necessarily have the most overall influence, will each be likely to have higher levels of influence in specific product categories. As such, marketers can more accurately tailor messages to individual group members. 
Su, Fern and Ye (2003) found evidence that spouses do not tend to return coercion with coercion in a discrete purchase situation; however, they do tend to alternate use of strong influence measures across decisions. In addition, spouses' post-decision evaluations (such as perceived influence and satisfaction) may affect subsequent decision behaviors. This finding seems to suggest that purchase-decision processes are adaptive, and as such, why spouses change behavior over time.

Knowing that spouses do not always agree (Burns \& Hopper 1986; Kim and Lee 1996; Spiro 1983) and since husbands and wives typically do not have identical needs and wants, joint decision-making can present an important source of conflict between spouses (Kirchler 1990, 1995; Kirchler \& Wagner 1987; Qualls 1988; Ward 2003). Researchers have found that couples often use various influence strategies in an effort to sway their partners in the decision making process in an effort to minimize the likelihood of conflict (Lackman \& Lanasa 1993; Su, Fern and Ye 2003). Spiro (1983) found that in jointly purchased major durable goods, 88 percent of the couples said there had been disagreements in their decision-making. In her study, she identified six different influence strategies used by the spouses to complete the decision process. Similarly, Kirchler (1990) attempted to classify all acts that spouses use to get their own way in a joint decision situation. Kim and Lee (1996) developed a taxonomy of home-buyers based on the couple's influence strategy mix when resolving preference discrepancies in the actual purchase situation. Corfman and Lehman (1987) also incorporated influence factors when looking at the spousal decision making process. This study extends previous research on the use of influence tactics in the family decision making process by determining whether spouses use of influence tactics varies according to product category and/or the initial level of disagreement between spouses regarding the likelihood of product purchase.

Specifically, this study tested whether spouses were more likely to engage in the use of influence tactics in across or within product categories. The majority of marketing empirical research to date has considered that couples are faced with decisions involving within category product choices, such as which specific brand of television to buy or what toothpaste to choose. This study investigated how the joint decision making process may differ when spouses are faced with across category preferences - basically when he wants to purchase an item from one product category and she wants an item from a different product category. For instance, does the use of influence tactics vary by spouses when he wants a big screen TV and she wants a home security system? Limited resources in most households may dictate that both purchases cannot be made (at this time) and, as a result, one spouse must concede to the other spouses' preferred product choice. Thus, in across category product choices, one spouse "wins" in that his/her preferred product is purchased and the other spouse "loses" in that he/she compromises on the product selected. Within category product choices are seen by this author as more likely to be considered a "win/win" scenario for both spouses because the family jointly benefits from a product purchased, even if it is not the specific brand or model preferred by the spouses individually. Ward (2003) found evidence to support the distinction between across versus within product category choices in a related paper exploring product category in relation to the level of disagreement experienced by the spouses and the relative conflict they reported. When looking at within category product choices in a purchase situation the relationship between level of disagreement and relative conflict was not statistically significant; however, the relationship was highly significant when looking at across category product choices only.

Also of interest in this study is whether the spouses' use of influence tactics changes significantly with the initial level of disagreement (high or low) experienced by the couple regarding the potential product purchase. It is expected that the use of influence may differ when couples strongly disagree at the onset of the decision process regarding which product should be purchased versus when the couple experiences a lower level of disagreement regarding the product(s) in question. Less of a compromise is required when couples experience a lower level of disagreement; therefore the likelihood of the spouses using influence tactics is predicted to be less in those decision processes as well. Thus, this research addresses the following questions:

1. Are spouses more likely to use influence tactics when making a joint decision involving across category product choices than when decisions involve within category product choices only?

2. Does the level of initial disagreement present between the spouses (high or low) affect the use of influence tactics when the couples make a joint purchase decision? 
Commuri and Gentry (2000) state that "there is little evidence of research that first examined which products entail joint decision making among informants and then investigated decision making for those products" (p. 19) (with the exceptions of Corfman and Lehmann (1987) and Ruth and Commuri (1998)). This study will attempt to help to bridge that lack of research by distinguishing across versus within product category choices in joint spousal purchase decisions, focusing on the role of influence in the decision process.

\section{INFLUENCE LITERATURE OVERVIEW}

Although family decision making has been a popular research topic among consumer behaviorists (Davis 1976; Lackman \& Lanasa 1993; Wolgast 1958), there has been a lack of work on family decision making regarding across category choices, how they may compare to within category choices, and the impact of these decisions on spouses. Conversely, the use of influence strategies has been widely researched in marketing and consumer behavior from many different perspectives. Deciding that there must be some recognizable process(es) that couples engage in when making decisions, Spiro (1983) conducted one of the first studies to examine the strategies used by individual spouses in making joint purchase decisions. Spiro found that most couples reported using influence strategies in low to moderate levels; however, manipulative people reported using all the strategies extensively. Also, if one spouse did not make strong attempts to use influence strategies, neither did the other spouse; however, if an individual reported that he or she did not use a particular strategy, the spouse often disagreed and said that he or she did (Spiro 1983).

Kirchler $(1988,1990)$ derived a typology of 18 influence tactics that couples may use in joint purchase decisions. To test these notions, Kirchler (1990) interviewed 35 married couples in a pilot study in which he presented the couples with six purchasing vignettes involving areas of personal conflict. He found strong support for the 18-item typology of influence strategies. The most commonly mentioned strategies from the typology are reason (19\% of cases) and bargaining strategies (trade-offs: $14 \%$; integrative bargaining: $19 \%$ ). '

In 1993, Kirchler followed up his pilot study, arguing that "decision making in intimate relationships can hardly be conceived of as a highly structuralized process" (p. 406). Given that spouses will not always have corresponding goals in joint decision situations, they will seek to fulfill their own goals while simultaneously dealing with the needs and goals of their spouse. Ultimately, disagreements will occur. To successfully solve the disagreements, the individual spouses must adopt some sort of tactics that allow for a decision satisfactory to both spouses. The purpose of Kirchler's (1993) study was to determine how couples muddle through the unstructured process of reaching a purchase decision while trying to satisfy both spouses and not damage the relationship. Kirchler presented couples with decisions involving distributional tasks (similar to across product category choices), where spouses were faced with limited resources and conflicting desires. Here, couples were found to use primarily negotiation tactics and reasoning. The most frequently used tactics were trade-offs and integrative bargaining (Kirchler 1993). Women were more likely to report leaving the scene, searching for integrative solutions, and yielding according to roles. Men were more likely to use rewards, buy autonomously, or decide according to roles. Given the broad scope of the influence literature, several other possible influence determinants have been identified.

\section{POSSIBLE INFLUENCE DETERMINANTS}

\section{Marital Satisfaction}

Research examining marital satisfaction has shown that happy spouses are more willing to yield in a conflict situation if the other spouse claims to have a strong desire for or interest in a product or commodity (Corfman \& Lehmann 1987; Kirchler 1988). Spiro (1983) also reported that happy spouses were more likely to be grouped as noinfluencers or light-influencers, whereas unhappy spouses were more commonly in the group of heavy influencers.

\section{Family Power}

Several earlier studies have shown that wives exert the primary influence on joint decision-making within a family structure, especially decisions affecting product choice and purchase (Ochsman 1979; Wolgast 1958). Also, when responses were obtained for both husbands and wives, their perceptions usually differ from each other (Burns \& 
Hopper 1986; Spiro 1983). In a fairly large-scale study, Howard, Blumstein, and Schwartz (1986) contacted over 6,000 U.S. couples (including heterosexual married couples and cohabitors, male homosexual couples, and lesbian couples), asking them to answer independently a lengthy questionnaire, which the researchers then followed up with random in-depth interviews. The questionnaire included such items as, "When your partner wants you to do something you do not want to do, how often does he/she do each of the following?" Twenty-four different possible influence tactics were identified and then factor analyzed. Six categories of influence strategies were identified as a result, including: manipulation, supplication, bullying, autocracy, disengagement, and bargaining (Howard, Blumstein, \& Schwartz 1986).

\section{Relationship Duration}

The duration of the relationship was also believed to be a factor in the choice of influence tactics. Kirchler (1993) found that couples that had been together for fewer years were more likely to use influence tactics on their partners than spouses in relationships that were more long-standing. He suggested that "when the honeymoon is over and spouses return to everyday life affairs, they may also move from intense and time-consuming joint decisions toward autonomous decisions" (Kirchler 1993, p. 412). Spiro (1983) also found some support for this notion. She found older couples with adult children to be most heavily concentrated in her group of light influencers.

\section{Cultural Effects}

Broadening the study of family decision making, several studies appear to have shifted their focus from who makes a decision within a family and how that decision is made to effects of culture and subculture on decisionmaking within the family unit. Cohen and Kaufman (1991) looked at the impact of subculture on decision making in African-American households. The authors conducted telephone surveys matching samples of blacks and whites regarding nine decisions common in U.S. households. Respondents were asked about relative influence during three stages: problem recognition, search for information, and final decision. They found that the African American subculture does affect spousal decision-making, but does not result in wife dominance. Rather, African-American spouses are more likely to be independent in their decision-making, whereas white spouses are more likely to be syncratic.

On the other hand, hispanic wives perceived significantly more husband-dominant decisions and fewer joint decisions than did caucasian wives. In a fairly large scale study of 600 Spanish families, Martinez and Polo (1999) found that joint decisions were common only in young households where the wife worked. If the wife did not work, or the couple had been married for many years, the husband was the primary decision maker. Webster (1994) also found a positive relationship between Hispanic ethnic identification and husband dominance, supporting earlier findings by O'Guinn, Faber and Imperia (1986). The lower the Hispanic identification by wives, the more likely they were to experience equality in decision making, although the husband was still acknowledged as the primary decision maker. These findings appear to indicate a transition in Hispanic households between those likely to maintain the behavioral patterns and values of the parent culture, versus those households which are becoming assimilated into a larger, less traditional host society in which wives are given more decision making authority.

\section{Resource Allocation}

Sociologists have studied the relationship between money and power in a relationship since the 1970s when Cromwell and Olson (1975) found that the partner with the larger income is likely to play a more dominant role in decision-making. In addition, researchers found that wives who have paid employment have more say than those wives who work only at home (Scanzoni 1979).

Particular attention has been paid to the allocation of funds within the household (Pahl 1980, 1995; Vogler \& Pahl 1994). Studies have shown that households in which the wife works full-time and where the husband's role as primary breadwinner is not traditionally held, result in more equitable household financial arrangements (Vogler \& Pahl 1993). However, Morris (1988) concluded that while sharing and joint partnership seems more common now than in the past, actual practices of financial allocation have not changed to a large degree. 


\section{HYPOTHESES}

The literature reveals that husbands and wives often are not able to accurately predict the choice of their spouse in specific decision situations (Davis, Hoch \& Ragsdale 1986; Quarm 1981). Family members will often disagree about the desirability of various alternatives. This disagreement may result in contradictory desires by spouses for products in different product categories. During the period when various alternatives are being considered, each spouse may attempt to influence the other toward his or her preferred position. To further broaden our understanding of the spousal decision making process, these hypotheses will examine whether or not spouses use influence tactics in varying degrees to sway their partner in decisions involving differing product categories and differing levels of initial spousal disagreement. In addition, the question of whether couples initially experienced high or low levels of disagreement regarding the likelihood of product purchase will be examined to determine whether the level of disagreement present between the spouses significantly impacted the use of influence tactics by the spouses.

The impact of spousal influence tactics is expected to be stronger in across product category choices than in within product category choices. This effect is expected because across category choices involve decisions where one spouse will "win" getting the product of his/her choice, and the other spouse "loses" in the sense that his/her preferred product is not chosen. In this type of decision process, spouses are more likely to use influence tactics in an attempt to sway their partner towards agreeing with their product choice while avoiding direct conflict in coming to a final product decision. Although influence tactics may also be used in within category product decisions, it is expected that they will probably be used less often or to a lesser degree because the spouses may not have as strong a need to influence their partners when making decisions involving products from within the same product category where both spouses are essentially "winners," in that the product is purchased for the family even if it is not the brand/model preferred by both spouses. Thus, Hypothesis One states:

$\mathbf{H}_{1}$ : Across category joint product decisions by couples should produce a greater use of perceived influence tactics than within category joint product decisions.

Perceived influence tactics are thought to be more likely to be used in decisions involving choices where the initial level of disagreement between the spouses was high versus low. When disagreement is low, spouses may not feel as great a need for influence tactics because the opportunity for compromise is greater, or possibly the decision may not be seen as important to each spouse individually. Similar to across category product decisions, decisions involving high levels of disagreement may result in one spouse being seen as "winning" the joint decision process and the other as "losing" depending on whether his/her product is ultimately purchased. Believing that conflict is more likely to occur when initial disagreement is high, many spouses may resort to more frequent use of or more different types of influence tactics in an effort to reach a successful joint decision without engaging in open conflict with their spouse in order to preserve family harmony. As a result, Hypothesis Two states:

$\mathbf{H}_{2}$ : $\quad$ High levels of disagreement should produce a greater use of perceived influence tactics than low levels of disagreement.

Using a similar rationale, the effects expected between the use of perceived influence tactics in product category choices and the use of perceived influence tactics based on the level of disagreement should be even more pronounced when product category and the level of disagreement are looked at together. In other words, the relationship expected between high levels of disagreement and influence should be even stronger when involving across product category decisions than when involving within category product decisions. This prediction is based on the authors' expectation that the highest level of potential conflict between spouses is expected to be on decisions involving across category product choices on which the spouses had initially experienced high levels of disagreement regarding the likelihood of product purchase. These decisions would seem to be the most likely to create conflict between spouses, therefore they are also predicted to be most likely to generate an elevated use of influence tactics in an effort to avoid, or at least minimize, possible conflict. Conversely, when spouses are facing within category choices involving low levels of disagreement, it is predicted that there will be a lower use of influence because the possibility of conflict does not appear as likely. Therefore, Hypothesis Three states: 
$\mathbf{H}_{3}$ : $\quad$ For across product category decisions, high levels of disagreement should result in higher levels of perceived influence tactics. However, for within product category decisions, there should be no difference between high and low levels of disagreement on the perceived influence tactics measure.

\section{METHODOLOGY}

While early research often involved responses by only one spouse, typically the wife (Davis 1976; Wolgast 1958), more recent research stresses the importance of gaining input from both spouses (Kirchler 1993, 1995; Spiro 1983). As a result, this study involves both husbands and wives participating in a study in which all statistical models are partitioned into across versus within product categories. Twelve influence measures (Corfman \& Lehmann 1987) were self-reported by individual spouses to determine the impact of spousal influence tactics on the joint decision making process.

\section{Subjects}

A total of 69 couples were recruited from various church, school, and community groups in the Middle Tennessee area to participate in this study, with only 61 couples completing the entire task. Each couple received $\$ 10$ for their participation and an opportunity to win a $\$ 500$ grand prize. Participating couples consisted of subjects in a range of ages, incomes, education, number of hours worked outside the home, number of years married, and number of children (See Table 1).

Table 1: Subject Demographics

\begin{tabular}{|l|c|c|c|c|c|c|}
\hline AGE & \multicolumn{3}{|c|}{ MALES (n=61) } & \multicolumn{3}{c|}{ FEMALES (n=61) } \\
\hline & FREQ. & \% & CUM. \% & FREQ. & \% & CUM. \% \\
\hline $18-25$ & 4 & 6.6 & 6.6 & 6 & 9.8 & 9.8 \\
\hline $26-34$ & 12 & 19.7 & 26.2 & 9 & 14.8 & 24.6 \\
\hline $35-44$ & 22 & 36.1 & 62.3 & 27 & 44.3 & 68.9 \\
\hline $45-54$ & 12 & 19.7 & 82.0 & 11 & 18.0 & 86.9 \\
\hline $55-64$ & 8 & 13.1 & 95.1 & 5 & 8.2 & 95.1 \\
\hline Over 64 & 3 & 4.9 & 100.0 & 3 & 4.9 & 100.0 \\
\hline
\end{tabular}

\begin{tabular}{|l|c|c|c|c|c|c|}
\hline INCOME & \multicolumn{3}{|c|}{ MALES } & \multicolumn{3}{c|}{ FEMALES } \\
\hline & FREQ. & \% & CUM. $\%$ & FREQ. & \% & CUM. \% \\
\hline Less than $\$ 7,500$ & 3 & 4.9 & 4.9 & 15 & 24.6 & 24.6 \\
\hline$\$ 7,500$ to $\$ 14,999$ & 3 & 4.9 & 4.9 & 9 & 14.8 & 39.3 \\
\hline$\$ 15,000$ to $\$ 24,999$ & 8 & 13.1 & 23.0 & 15 & 24.6 & 63.9 \\
\hline$\$ 25,000$ to $\$ 39,999$ & 11 & 18.0 & 41.0 & 7 & 11.5 & 75.4 \\
\hline$\$ 40,000$ to $\$ 59,000$ & 17 & 27.9 & 68.9 & 9 & 14.8 & 90.2 \\
\hline$\$ 60,000$ to $\$ 99,999$ & 14 & 23.0 & 91.8 & 2 & 3.3 & 93.4 \\
\hline More $\$ 100,000$ & 5 & 8.2 & 100.0 & 4 & 6.6 & 100.0 \\
\hline
\end{tabular}

\begin{tabular}{|l|c|c|c|}
\hline TOTAL HOUSEHOLD INCOME & FREQ. & \% & CUM. \% \\
\hline Less than $\$ 14,999$ & 2 & 3.3 & 3.3 \\
\hline$\$ 15,000$ to $\$ 24,999$ & 1 & 1.6 & 4.9 \\
\hline$\$ 25,000$ to $\$ 39,999$ & 13 & 21.3 & 26.2 \\
\hline$\$ 40,000$ to $\$ 59,000$ & 14 & 23.0 & 49.2 \\
\hline$\$ 60,000$ to $\$ 99,999$ & 22 & 36.1 & 85.2 \\
\hline More than $\$ 100.000$ & 9 & 14.8 & 100.0 \\
\hline
\end{tabular}

\begin{tabular}{|c|c|c|c|}
\hline DESCRIPTION OF COUPLES $(n=61)$ & MEAN & MINIMUM & MAXIMUM \\
\hline Number of years married & 16.91 & 0 & 54 \\
\hline Average hours per week male works & 39.62 & 0 & 75 \\
\hline Average hours per week female works & 19.70 & 0 & 50 \\
\hline Number of children in household & 1.54 & 0 & 4 \\
\hline
\end{tabular}




\section{Design}

A 2 (product category: across versus within) X 2 (level of disagreement: high versus low) between subjects design was used in testing this study. The stimuli consisted of products and services within a wide price range ( $\$ 15$ to $\$ 4,000)$ that represented purchases that couples would likely make over the course of their marriage. The majority of products were priced between $\$ 50$ and $\$ 400$, assuming that these products would have a higher likelihood of purchase within a two-year period than more expensive items, but also that the costs were high enough to have possible input from both spouses. Product selection was based primarily on the products used by Corfman and Lehmann (1987), being updated to account for new technologies and geographic location of the study's participants. The products were grouped into eight separate categories for within category versus across category evaluations. A total of 54 different products was evaluated by subjects and included choices in home entertainment, furniture, kitchen appliances, nonhome entertainment, household chores, office/education, environment/health, and charitable contributions.

\section{Data Collection}

The data collection consisted of two distinct stages. In the first stage, a mail survey was sent in which subjects were asked to complete an Individual Product Questionnaire without discussing their responses in any way with their spouse. The Individual Product Questionnaires were based on those used by Corfman and Lehmann (1987). The questionnaires the spouses received were identical and required the spouses to evaluate the likelihood of purchasing 54 products over the next two years (100 point scales) and what price level they would be willing to spend for the product (selecting one of three options). The first questionnaire also contained demographic information for each spouse. Demographic data included gender, age, number of years married, number of hours worked per week, personal income, household income, education, and number of children.

\section{Second Data Collection Phase}

The responses on the first questionnaire were used to create product pairings for the second stage of data collection, the joint interview. Most of the joint interviews with the couples were conducted in their homes, except for three occasions when the couples requested that the interviewer meet with them in a more convenient location. Based on their ratings of the 54 products/services, couples were randomly placed in one of two primary categories: (1) couples who would be presented choices of products from within product categories $(n=29)$, or (2) couples presented with choices from across product categories $(n=32)$.

The spouses were shown a series of products/services, two at a time. The joint decisions created were chosen for their propensity to generate conflict between the two spouses. The product pairings consisted of two products on which the couple had disagreed in the initial questionnaire. Specifically, of the two products paired together, the female had initially preferred one product (product b) and the male had preferred the other (product a). The product pairings were designed (and categorized) by the researcher to include products on which the couples had either a high or low level of disagreement as determined in Stage 1. High disagreement was defined as situations where both of the spouses assigned at least 25 or more points for his/her product than did his/her spouse in the individual survey. All other paired decisions were classified as low levels of disagreement.

In a controlled meeting with the researcher, the spouses individually rated the likelihood of purchasing the items within the next two years, dividing 100 points between the two items (100 point constant sum scales). These numbers were used to indicate preference intensity for the products. A fifty-fifty evaluation was not allowed in that it indicated no decision for one product over the other. Couples received an average of eight product decisions.

After evaluating the products individually, the couples then repeated the process except that this time they were presented the product pairings and told they were free to discuss the products with their spouses. The goal for the couple was to come to a joint consensus on which of the two products would most likely be acquired and to divide 100 points between the two products indicating their joint decision. The couple completed this step for each of the product pairings in order to create a decision history for the spouses. 
The final step of the data collection was a Post-Questionnaire following the interview. Spouses were again required to do this individually. The Post-Questionnaire consisted of three reality and manipulation check questions (questions 1 through 3, 5-point Likert scales) and twelve influence tactic questions (from Corfman \& Lehmann's (1987) original data collection). Spouses responded that they found the task to be realistic (mean equal to 4.2, $1=$ did not act at all the same as in a real situation, $5=$ acted exactly the same as in a real situation); couples did not feel as if they acted any differently with the interviewer present (mean equal to 4.3); and husbands/wives had not discussed the first questionnaire with their spouse (mean equal to $1.59,1=$ not at all, $5=$ extensively).

\section{Independent Variables}

The independent variables used in this study to test the hypotheses consisted of product category and level of spousal disagreement.

Product Category. Product category is a measure of the across versus within decision effects. This dichotomous variable is coded 0 if the decision is from a within product category and 1 if it is from an across product category.

Level of Spousal Disagreement. The level of spousal disagreement is a dichotomous measure of the level of disagreement between spouses when they individually rated the products later used in the joint paired product decisions. This variable is coded 0 for low level of disagreement (when spouse assigned fewer than twenty-five points more for his/her product than his/her spouse in the individual survey), and coded 1 for high level of disagreement (when spouse assigned at least twenty-five or more points for his/her product than his/her spouse in the individual survey). The twenty-five-point cutoff was established because it represented as close as possible a 50/50 split of the data joint decisions into low and high levels of disagreement joint decisions. The final totals were that 218 of the decisions (45.4\%) were classified as low disagreement decisions and 262 were classified as (54.6\%) high-level disagreement decisions.

\section{Dependent Variable}

Perceived couple influence tactics. As noted earlier, there is strong support for the idea that spouses use influence tactics when making joint spousal decisions (Kirchler 1990, 1993; Spiro 1983). As a result, 12 items garnered from Corfman and Lehmann's (1987) research were included for this study. Scale questions asked spouses to determine how much as a couple they used various influence tactics during their joint decision making process. With answers ranging from "not at all" to "very much", spouses were asked such questions as how much/how often did they: Take turns? Try to compromise? Bargain? Decide of favor of the person who was most emotional? Decide of favor of the person who minds conflict least?

A factor analysis was done to determine the structure of the influence scale. The Cronbach alpha measure of sampling accuracy for the factor analysis was .80 (see Table 2). Six of the 12 items from the scale loaded on the first factor and six items loaded on the second factor. The proportion of the variance explained by each factor was .76 and .20 respectively. Given the contributions of each factor to this influence construct, subsequent analyses were run with each factor separately. Based on these results, the model was run using the stronger of the two influence variables and then rerun with the second influence variable. The results indicated that only the model using the first factor produced significant findings; the model using the second influence factor was not significant. Therefore, only the results from the model using the first influence factor are reported in this study.

\section{RESULTS}

This study examined which factors in the joint decision making process impacted the level of perceived influence tactics that couples experienced when undergoing a series of product choices. The hypotheses predicted that couples would be more likely to use influence tactics in an effort to persuade their spouse in across, rather than within, product categories. Spouses are also thought to be more likely to engage influence tactics when spouses experienced high (versus low) disagreement initially regarding the likelihood of product purchase. This study's hypotheses were generally supported by the results. 
Table 2: Factor Analysis Results for Couple Influence Tactics Factor One Loading Results

\begin{tabular}{|c|c|}
\hline Factor One Loading Results & Factor Scores \\
\hline Question A & 0.19 \\
\hline Question B & -0.34 \\
\hline Question C & 0.29 \\
\hline Question D & -0.09 \\
\hline Question E & -0.01 \\
\hline Question F & 0.81 \\
\hline Question G & 0.82 \\
\hline Question H & 0.79 \\
\hline Question I & 0.72 \\
\hline Question J & 0.76 \\
\hline Question K & 0.80 \\
\hline Question L & 0.15 \\
\hline
\end{tabular}

\begin{tabular}{|c|c|}
\hline Factor Two Loading Results & Factor Scores \\
\hline Question A & 0.41 \\
\hline Question B & 0.43 \\
\hline Question C & 0.30 \\
\hline Question D & 0.40 \\
\hline Question E & 0.44 \\
\hline Question F & 0.07 \\
\hline Question G & 0.17 \\
\hline Question H & 0.29 \\
\hline Question I & -0.08 \\
\hline Question J & -0.17 \\
\hline Question K & -0.27 \\
\hline Question L & -0.12 \\
\hline
\end{tabular}

The main effect for product category on perceived influence tactics was significant, $\underline{F}(1,476)=9.28, \underline{p}<$ .001 , Ms: Across $=5.78$, within $=5.15$. Couples were more likely to use influence tactics in across category product choices than within category product decisions, supporting Hypothesis 1. An overview of the test results is shown in Table 3.

The main effect for level of disagreement was marginally significant, $\underline{F}(1,476)=3.14, \underline{p}<.10$, Ms: High $=$ 5.57, Low $=5.26$. Couples were marginally more likely to use influence tactics when the level of disagreement is high than when the level of disagreement is low. As a result, Hypotheses 2 is marginally supported.

These main effects must be qualified by the marginally significant interaction of product category by level of disagreement, $\underline{\mathrm{F}}(1,476)=2.83, \underline{\mathrm{p}}<.10$. Decomposition of this interaction revealed that the level of perceived influence tactics used and its positive relationship to high levels of disagreement is significantly greater in across category product decisions than in within category decisions, $\underline{\mathrm{F}}(1,476)=5.73, \underline{\mathrm{p}}<.01$ versus $\underline{\mathrm{F}}(1,476)=.01, \underline{\mathrm{p}}<$ .94. The contrast effects reveal that the level of disagreement is not significantly related to influence when the product choices involve within category products only. However, when the product choices involve across category products only, the level of disagreement is highly significant for influence tactics. Therefore, Hypothesis 3 is supported (Tables $3 \& 4$ ). For across product category decisions, high levels of disagreement result in higher levels of perceived influence tactics used by the couples, but this does not hold true for within category decisions. Figure 1 graphs the two-way interaction of product category by level of disagreement on perceived influence tactics. 
Table 3: Influence 2 X 2 ANOVA Model $^{1}$ Results:

Means for INFLUENCE Across Levels of Independent Variables and Model Test Statistics

Means for INFLUENCE Across CATEGORY (Verification of $\mathrm{H}_{1}$ and CATEGORY Main Effect)

\begin{tabular}{|l|c|}
\hline CATEGORY = 0 (Within Product Category) & CATEGORY = 1 (Across Product Category) \\
\hline 5.153 & 5.778 \\
\hline
\end{tabular}

CATEGORY Main Effect: F Statistic $=9.28$, P-value $=.00(1 \mathrm{DF})$

Means for INFLUENCE Across LEVEL OF DISAGREEMENT (Verification of $\mathrm{H}_{2}$ and DISVAR Main Effect):

\begin{tabular}{|l|c|}
\hline DISVAR = 0 (Low Level of Disagreement) & DISVAR = 1 (High Level of Disagreement) \\
\hline 5.260 & 5.566 \\
\hline
\end{tabular}

DISVAR Main Effect: F Statistic $=3.14$, P-Value $=.07(1 \mathrm{DF})$

Means for INFLUENCE Across CATEGORY by LEVEL OF DISAGREEMENT (Verification of $\mathbf{H}_{3}$ )

\begin{tabular}{|c|c|c|c|c|c|c|c|}
\hline CATEGORY $=0$ & $\begin{array}{c}\text { DISVA } \\
\mathbf{R}=\mathbf{0}\end{array}$ & $\begin{array}{c}\text { CATEGORY } \\
=0\end{array}$ & $\begin{array}{c}\text { DISVA } \\
\mathbf{R}=1\end{array}$ & $\begin{array}{c}\text { CATEGORY } \\
=1\end{array}$ & $\begin{array}{c}\text { DISVAR } \\
=0\end{array}$ & $\begin{array}{c}\text { CATEGORY } \\
=1\end{array}$ & DISVAR = 1 \\
\hline 5.144 & & \multicolumn{2}{|c|}{5.160} & \multicolumn{2}{|c|}{5.387} & \multicolumn{2}{|c|}{6.003} \\
\hline
\end{tabular}

CATEGORY*DISVAR Interaction Effect:

DISVAR at high level of CATEGORY (cell 3 versus cell 4):

F Statistic $=2.83, \mathrm{P}-$ Value $=.09(1 \mathrm{DF})$

DISVAR at low level of CATEGORY (cell 1 versus cell 2): $\quad$ F Statistic $=0.01, \mathrm{P}-$ Value $=.94(1 \mathrm{DF})$

${ }^{1}$ The Influence Model contains the following variables regressed on INFLUENCE in an ANOVA Model. INFLUENCE = couple's perception of the influence tactics used in joint couple decisions, and is an average of the influence questions loading highest on factor one, questions $\mathrm{f}, \mathrm{g}, \mathrm{h}, \mathrm{i}, \mathrm{j}$, and $\mathrm{k}$. CATEGORY is a dichotomous variable coded 0 for a within category choice decision and coded 1 for an across category choice decision. DISVAR is a dichotomous measure of the level of disagreement between spouses when they individually rated the products later used in the joint paired product decisions. DISVAR is coded 0 for low level of disagreement (when spouse assigned fewer than twenty-five points more for his/her product than his/her spouse in the individual survey), and coded 1 for high level of disagreement (when spouse assigned at least twenty-five or more points for his/her product than his/her spouse in the individual survey).

Table 4: Means and Standard Deviations for Perceived Influence Tactics Across Product Category Choice by Level of Disagreement

\begin{tabular}{|l|c|c|}
\hline \multirow{2}{*}{} & \multicolumn{2}{|c|}{ PRODUCT CATEGORY } \\
\cline { 2 - 3 } Low Level of Disagreement & WithinProduct & Across Product \\
\cline { 2 - 3 } & 5.14 & 5.39 \\
High Level of Disagreement & $(1.88)$ & $(2.03)$ \\
\hline
\end{tabular}

Standard deviations are in parentheses. 
Figure 1

Two-way Interaction of Category Choice by Level of Disagreement on Perceived Influence Tactics

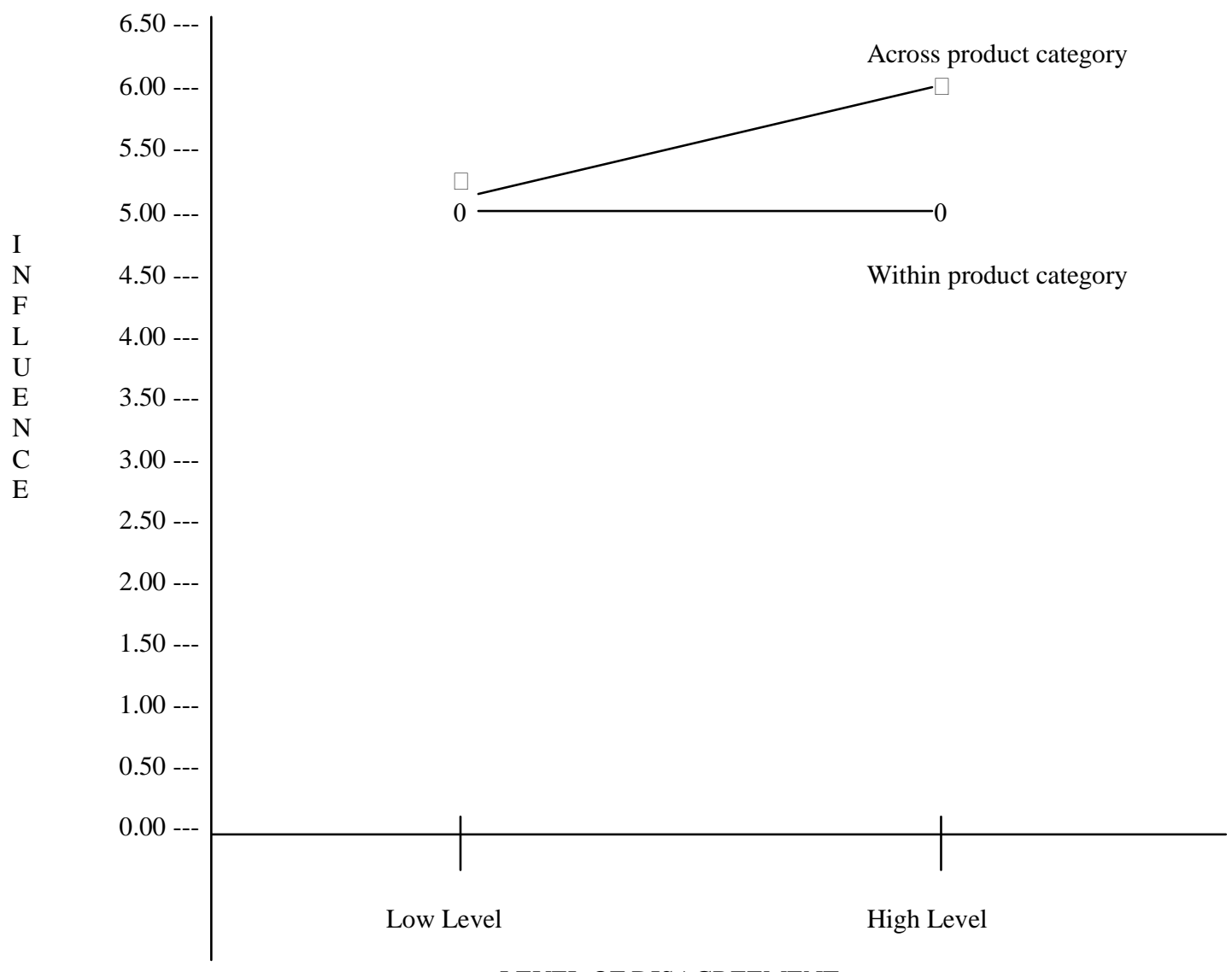

LEVEL OF DISAGREEMENT

\section{CONCLUSION}

Two primary findings resulted from this study: (1) The results indicate that couples are more likely to use influence tactics in across category decisions than within. (2) Within product category decisions did not produce significant use of influence at either high or low levels of disagreement whereas across category product choice decisions did. Specifically, in across product category decisions, high levels of disagreement produced greater use of influence tactics than low levels of disagreement. Thus, spouses do appear to engage in a greater use of influence tactics when deciding among products from different product categories, such as a new big screen TV versus a home security system.

Also, in across product category decisions, high levels of disagreement produced greater use of influence tactics than low levels of disagreement. It appears that when looking at product options from two different categories, couples perceived significantly higher levels of influence used if they had initially disagreed on the likelihood of product purchase than if they had not. This finding was not true of within category choices. Apparently, influence tactics may be more likely to be used by spouses in an attempt to influence the category of the final product chosen and, at the same time, minimize the possibility of generating conflict in the relationship when spouses had experienced high levels of disagreement initially regarding the likelihood of product selection. 
A better understanding of how spousal influence is used in family purchase decisions can help marketers to identify influential spouses, to better predict when influence may likely be exerted by the spouses, and to better target communication marketing messages to the spouse who may have primary decision making authority regarding the product decision in question (Su, Fern, and Ye 2003). Prior research has shown that spousal influence varies from one decision to another and that past decision history impacts the current decision process (Corfman and Lehmann 1987). As research grows to support the theory that spousal decisions are interrelated (past, present, and future), then a better understanding of the decision process can possibly enable marketers to design specific message appeals for targeting specific spouses.

While every effort was made to ensure a good representation of subjects, this study has limited validity in that these findings may not generalize to couples in other cultures and geographic regions outside of the Southeast. Future research could examine possible differences in cross-cultural couples or couples of varying ethnic/racial backgrounds. Also, though subjects reported that they found the decision making process to be realistic, when actual dollars are involved and relationships at stake, actual behaviors may differ from those taken in this study. A multistage study could focus on anticipated purchase behaviors and then follow-up on what purchase decisions were actually made by the couples at the point of purchase. Future research could also address the issue of gender roles in decision making; i.e., whether males and females perceive their roles to be equal in the decision making process.

Participation by both spouses in this study enabled the researcher to make this task more realistic in examining the actual decision making process couples encounter when faced with product decisions. With spouses reporting increasing levels of "time poverty" and lifestyles growing ever more fast-paced, it is increasingly difficult to gain cooperation by spouses in completing this type of study. However, as roles change for spouses and family dynamics become more and more hectic, it is important for researchers to continue this type of research in an effort to capture the changes that may be occurring within family decision making as a result of changing family structures.

\section{REFERENCES}

1. Aribarg, Anocha, Neeraj Arora, and H. Onur Bodur (2002), "Understanding the Role of Preference Revision and Concession in Group Decisions," Journal of Marketing Research, 39 (August), 336-345.

2. $\quad$ Arora, Neeraj and Greg M. Allenby (1999), "Measuring the Influence of Individual Preference Structures in Group Decision Making," Journal of Marketing Research, 36 (August), 476-487.

3. Burns, Alvin C. and Jo Anne Hopper (1986), "An Analysis of the Presence, Stability, and Antecedents of Husband and Wife Purchase Decision Making Influence Assessment Agreement and Disagreement," in Advances in Consumer Research, Vol. 13, ed. Richard J. Lutz, 175-180.

4. Cohen, Judy and Carol J. Kaufman (1991), "The Impact of Subculture on Black Spousal Decision Making," Research in Consumer Behavior, 5, 1-31.

5. Commuri, Suraj and James W. Gentry (2000), "Opportunities for Family Research in Marketing," Academy of Marketing Science Review, Vancouver.

6. Corfman, Kim P. and Donald R. Lehmann (1987), "Models of Cooperative Group Decision-Making and Relative Influence: An Experimental Investigation of Family Purchase Decisions," Journal of Consumer Research, 14 (June), 1-13.

7. Cromwell, Ronald E. and David H. Olson (1975), "Multidisciplinary Perspectives of Power," in Power in Families, ed. Ronald E. Cromwell and David H. Olson, New York: John Wiley, 15-36.

8. Davis, Harry L. (1976), "Decision Making within the Household," Journal of Consumer Research, 2 (March), 241-260.

9. Davis, Harry L., Stephen J. Hoch, and E.K. Easton Ragsdale (1986), “An Anchoring and Adjustment Model of Spousal Predictions," Journal of Consumer Research, 13 (June), 25-37.

10. Howard, Judith A., Philip Blumstein and Pepper Schwartz (1986), "Sex, Power and Influence Tactics in Intimate Relationships," Journal of Personality and Social Psychology, 51, 102-109.

11. Kim, Chankon and Hanjoon Lee (1996), "A Taxonomy of Couples Based on Influence Strategies: The Case of Home Purchase," Journal of Business Research, 36, 157-168.

12. Kirchler, Erich (1988), "Diary Reports on Daily Economic Decisions of Happy versus Unhappy Couples," Journal of Economic Psychology, 9, 327-357. 
13. Kirchler, Erich (1990), "Spouses' Influence Strategies in Purchase Decisions as Dependent on Conflict Type and Relationship Characteristics," Journal of Economic Psychology, 11, 101-118.

14. Kirchler, Erich (1993), "Spouses' Joint Purchase Decisions: Determinants of Influence Tactics for Muddling Through the Process," Journal of Economic Psychology, 14, 405-438.

15. Kirchler, Erich (1995), "Studying Economic Decisions Within Private Households: A Critical Review and Design for a 'Couple Experiences Diary,"' Journal of Economic Psychology, 16, 393-419.

16. Kirchler, Erich and Wolfgang Wagner (1987), "Marital Satisfaction and Conflict in Purchasing Decisions," Social Behaviour, 2, 99-103.

17. Lackman, Conway and John M. Lanasa (1993), "Family Decision-Making Theory: An Overview and Assessment," Psychology \& Marketing, 10 (March/April), 81-93.

18. Martinez, Eva and Yolanda Polo (1999), "Determining Factors in Family Purchasing Behaviour: An Empirical Investigation," The Journal of Consumer Marketing, 16, 5, 461-481.

19. Morris, Lydia (1988), "Employment, the Household, and Social Networks" in Employment in Britain, ed. D. Gallie, Oxford: Basil Blackwell.

20. Nelson, Margaret C. (1988), "The Resolution of Conflict in Joint Purchase Decisions of Husbands and Wives: A Review and Empirical Test," in Advances in Consumer Research, Vol. 15, ed. M. Houston, Provo, UT: Association for Consumer Research, 436-441.

21. O'Guinn, Thomas C., Ronald J. Faber, and Giovanna Imperia (1986), "Subcultural Influences on Family Decisionmaking," Psychology \& Marketing, 3, 305-317.

22. Ochsman, Robert B. (1979), "Husband/Wife Interaction in Making Purchase Decisions," The Journal of Psychology, 103, 145-157.

23. Pahl, Jan (1980), "Patterns of Money Management within Marriage," Journal of Social Policy, 9 (3), 313335.

24. Pahl, Jan (1995), "His Money, Her Money: Recent Research on Financial Organization in Marriage," Journal of Economic Psychology, 16, 361-376.

25. Park, C. Whan (1982), "Joint Decisions in Home Purchasing: A Muddling-through Process," Journal of Consumer Research, 9 (September), 151-162.

26. Qualls, William J. (1987), "Household Decision Behavior: The Impact of Husbands' and Wives' Sex Role Orientation," Journal of Consumer Research, 14 (December), 264-279.

27. Qualls, William J. (1988), "Toward Understanding the Dynamics of Household Conflict Behavior," in Advances in Consumer Research, Vol. 15, ed. M. J. Houston, Ann Arbor, MI: Association for Consumer Research, 442-448.

28. Quarm, Daisy (1981), "Random Measurement Error as a Source of Discrepancies Between the Reports of Wives and Husbands Concerning Marital Power and Task Allocation," Journal of Marriage and the Family, 43 (August), 521-535.

29. Ruth, Julie and Suraj Commuri (1998), "Shifting Roles in Family Decision Making," in Advances in Consumer Research, Eds. Joseph Alba and Wesley Hutchinson. Provo, UT: Association for Consumer Research, 400-406.

30. Scanzoni, John (1979), "Social Processes and Power in Families," in Contemporary Theories about the Family, Vol. 1, eds. Wesley R. Burr, Reuben Hill, F. Ivan Nye, and Ira L. Reiss, New York: Free Press, 295316.

31. Seetharaman, P. B., Andrew Ainslie, and Pradeep K. Chintagunta (1999), "Investigating House State Dependence Effects Across Categories," Journal of Marketing Research, 36 (November), 488-500.

32. Spiro, Rosann L. (1983), "Persuasion in Family Decision-Making," Journal of Consumer Research, 9 (March), 393-402.

33. Su, Chenting, Edward F. Fern, and Keying Ye (2003), "A Temporal Dynamic Model of Spousal Family Purchase-Decision Behavior,” Journal of Marketing Research, 40 (August), 268-281.

34. Vogler, Carolyn and Jan Pahl (1993), "Social and Economic Change and the Organization of Money in Marriage," Work, Employment and Society, 7 (1), 71-95.

35. Vogler, Carolyn and Jan Pahl (1994), "Money, Power and Inequality within Marriage," The Sociological Review, 42, 263-288. 
36. Ward, Cheryl B. (2003), "The Impact of Product Category and Level of Disagreement on Relative Conflict: Does Product Category Affect the Joint Decision Making Process for Spouses?" Academy of Marketing Studies Journal, 7 (1), 61-75.

37. Webster, Cynthia (1994), "Effects of Hispanic Ethnic Identification on Marital Roles in the Purchase Decision Process," Journal of Consumer Research, 21 (September), 319-331.

38. Wolgast, Elizabeth H. (1958), "Do Husbands or Wives Make the Purchase Decisions?" Journal of Marketing, 23, 151-158.

\section{NOTES}

